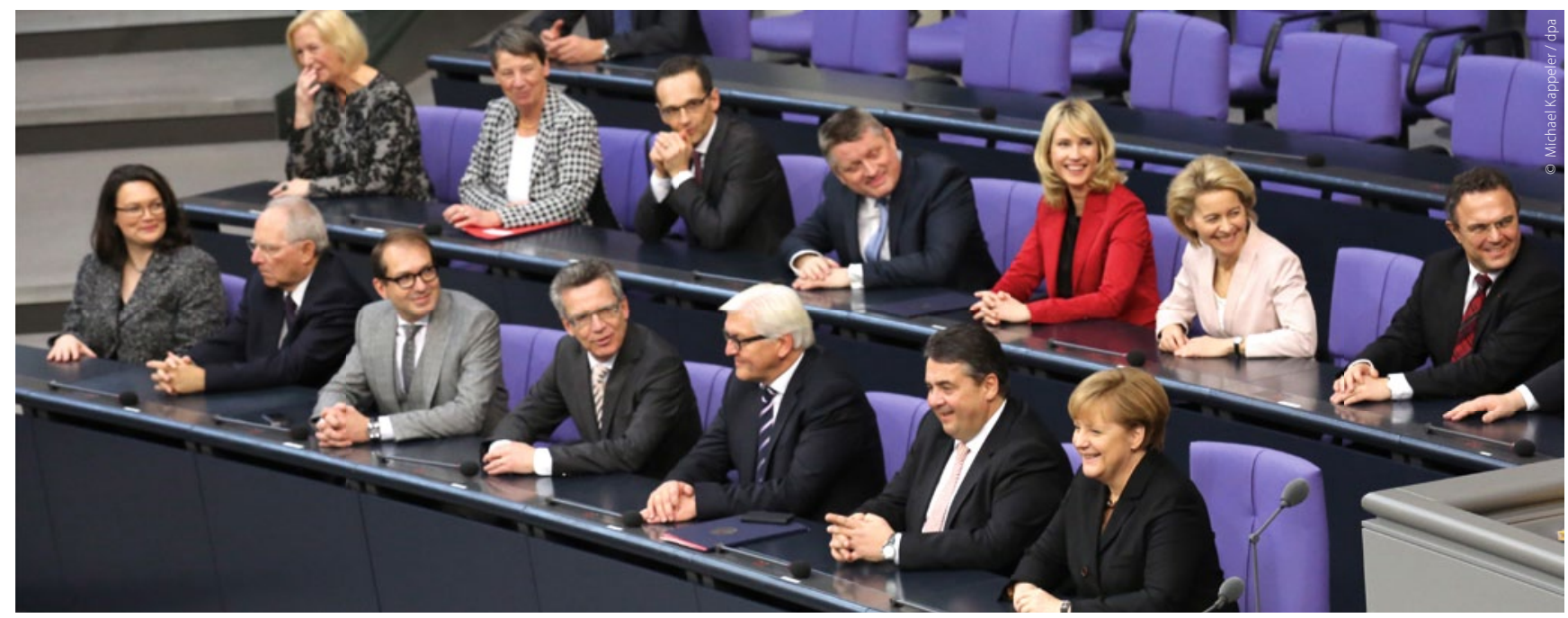

\title{
Dr. Harald Terpe, Obmann von Bündnis90/Die Grünen im Gesundheitsausschuss des Bundestages
}

Der großen Koalition fehlt die gemeinsame Vision, wie die Gesundheitsversorgung der Zukunft aussehen soll und wie diese solidarisch und demografiefest finanziert werden kann. Sie handelt nach dem Motto „Verwalten statt gestalten“.

Es bleibt bei der ungerechten und unsinnigen Trennung von gesetzlicher und privater Krankenversicherung. Bürokratische Scheinlösungen wie Terminservicestellen können nicht darüber hinwegtäuschen, dass die SPD entgegen ihres Wahlprogramms nicht für die Umwandlung von Kranken- und Pflegeversicherung in Bürgerversicherungen kämpft. Die gesetzlich Versicherten zahlen zukünftig alle Kostensteigerungen allein, da die Große Koalition in einer der ersten Amtshandlungen den Arbeitgeberbeitrag festgeschrieben hat.

Das Präventionsgesetz ist ein typisches Beispiel dafür, dass für Schwarz-Rot politische Prosa wichtiger ist als inhaltliche Substanz. Die Grundlagen für eine lebensweltbezogene und langfristig angelegte Prävention werden nicht gelegt. Bei der Umsetzung setzt die Koalition weiter ausschließlich auf die Kassen, statt Länder, Kommunen und die Menschen vor Ort mit einzubeziehen. Schwarz-Rot verpasst damit eine wichtige Chance, den Abbau ungleicher sozialer Gesundheitschancen voranzubringen.

Der Entwurf zum Versorgungsstärkungsgesetz lässt mutige Reformschritte vermissen. Er enthält kaum Impulse für eine stärkere, sektorübergreifende Versorgung, keine Schritte zu einer bedarfsgerechten Versorgungsplanung. Die Diskussion um die nötige stärkere Regionalisierung der Versorgungssteuerung ist offenbar spurlos an der Koalition vorbeigegangen.

Ob bei der Prävention oder in der Pflege, bei Krankenhäusern oder ambulanter Versorgung - überall scheint sich zu bewahrheiten: Große Koalition heißt k(l)eine Lösung.

Gesundheitsversorgung ist Daseinsvorsorge. Sie darf nicht durch weitere unnötige Bürokratie und Ökonomisierung zulasten der Versicherten und der im Gesundheitswesen Tätigen beeinträchtigt werden.

\section{Harald Weinberg, Gesundheitspolitischer Sprecher der LINKEN}

Die gesundheitspolitische Bilanz im ersten Jahr der GroKo ist traurig. Traurig deswegen, weil die wichtigsten Entscheidungen weder Verbesserungen für die Patientinnen und Patienten, noch für die Versicherten gebracht haben. Stattdessen wurden Partikularinteressen bedient.

Gleich das erste Gesetz, das SGB-V-Änderungsgesetz brachte die Absenkung des Herstellerrabattes für die Arzneimittelhersteller von 16 auf 7 Prozent. Zugegeben: Schön inszeniert war es ja. Die Koalition sprach nie von einer Absenkung, sondern von einer Erhöhung von sechs Prozent auf sieben Prozent. Und die Pharmalobbyisten jaulten aufgrund dieser Erhöhung dann auch laut auf und beschworen mal wieder das Ende der Medikamentenversorgung in Deutschland. Also legte die Bundesregierung noch eins drauf und beendete den Bestandsmarktaufruf - zulasten der Medikamentensicherheit und auf Kosten der Beitragszahler.

Das zweite große Gesetz, das FQWG, war dann zum Nutzen der Arbeitgeber. Die Höhe der Zusatzbeiträge, die die Versicher- ten ohne Arbeitgeberbeteiligung zahlen müssen, ist zukünftig nicht mehr gesetzlich gedeckelt. Alle Kostensteigerungen zahlen die Versicherten alleine. Damit hat die Bundesregierung mit SPD-Beteiligung eine Regelung geschaffen, die das Kapital mehr schont und die Arbeit mehr belastet als die bisherigen, unter einem FDP-Minister erdachten Zusatzbeiträge mit irgendwann greifendem Sozialausgleich.

Was wird kommen? Ein Präventionsgesetz, das zu kurz greift und nur Verhalten, nicht aber die Verhältnisse ändern will. Ein Versorgungsstärkungsgesetz, das den größten Konstruktionsfehler, die Sektorengrenzen, nicht überwindet.

Das alles ist keine Politik, die von den Versicherten her gedacht ist. Die Folgen derartiger Politik, die Partikularinteressen über das Interesse der Versicherten stellt, finden Sie, verehrte Zahnärztinnen und Zahnärzte, ja auch täglich in Ihren Praxen: Wer nicht draufzahlen kann, bekommt die schlechtere Versorgung. Das würden wir gerne ändern, am liebsten mit Ihnen gemeinsam. 